\title{
Demand Research based on Shared Interests of Member in Farmer Professional Cooperative Economic Organization
}

\author{
Bin PAN \\ College of Economics, Central University of Finance and Economics, Beijing, 100081, China \\ College of Business, Inner Mongolia University of Finance and Economics, Hohhot, 010070, China \\ billmusic2002@163.com
}

\begin{abstract}
The paper analyzes interest demands of members in farmer professional cooperative economic organization, and finds out the facing problems of interests demands, meanwhile appeal process dilemma model analysis. The study finds when achieving the Nash equilibrium of interest demand between farmers and leading enterprises, farmers' income will increase and farmer professional cooperative economic organization will be sustained and stable as well.
\end{abstract}

KEYWORD: Farmer Professional Cooperative Economic Organization; Interests Demand; Dilemma Model

\section{INTRODUCTON}

Under certain conditions Interest is the different needs or demands through the establishment of human social relationship, is a specific transformation form, which shows an active social relationship of the subject to the object, and constitutes the inner motivation of human behavior. As a member of farmer professional cooperative economic organization, its benefit demand is the basic needs but also the core problem, the essence is the distribution of interests. That is, the eventual result is of "sharing resources, sharing of benefits and risk sharing".

\section{MEMBER INTERESTS DEMANDS} ANALYSIS OF FARMER PROFESSIONAL COOPERATIVE ECONOMIC ORGANIZATION

\subsection{Interests Demands of Ordinary Farmers in Farmer Professional Cooperative Economic Organization}

Along with policy releasing of nation land circulation and the rising of modern intensive agriculture, traditional agriculture is quietly undergoing tremendous changes. The market of farmer production and consumption gradually changed from unshared housing to large family with tens of thousands of acres of land, meanwhile modern agricultural activities like production and wholesale of agricultural materials are common. That means traditional agricultural is broken and will be replaced by farmer professional cooperative economic organization. In farmer professional cooperative economic organization, farmers have four benefits: voting rights, ownership, trading rights and distribution rights of surplus, corresponding respectively play the roles of control, owner, user and patrons. In the context of maximum interest demands, benefit structure of farmer professional cooperative economic organization presents the following two typical evolution trends: one is transaction from the a buyout to property rights on farmers economic benefits, another is evolution from individuals account for large shares to dispersed ownership. Therefore, ordinary farmers produced below interest demands:

First, to get technical support and service. China's low level of education leads to the low quality of farmers with less knowledge, it is difficult to achieve scientific planting and breeding through their own efforts, so agricultural products of poor quality and low market competitiveness. Farmer professional cooperative economic organization can provide services from each link connected to the production, help farmers to master the science and technology and learn the advanced management experiences and market information and so on.

Second, to reduce the transaction costs. For agricultural price, producers and consumers are both not satisfied because of low purchasing price and high retail price, and the only ones to high profit from the whole process of agricultural products trade will be intermediary. Farmer professional cooperative economic organization can help reduce 
transaction link so as to avoid blind production and loss of profits.

Third, to get specialization and large-scale production. These factors of underdeveloped rural third industry and pure low income are driving farmers interest demand changing according to mode of production changes, thus forming the interest demands to join farmer professional cooperative economic organization. Farmer professional cooperative economic organization realize specialization and large-scale production through unified purchasing, production and sales to reduce the farmers' production and operation cost, and make it obtain the scale benefits.

\subsection{Interests Demand of Leading Enterprise in Farmer Professional Cooperative Economic Organization}

Farmer professional cooperative economic organization with leading enterprise driven is common in China. Leading enterprise establish economic ties with farmers by contracts to make sure to have sufficient and stable primary agricultural products, and at the same time give farmers the relatively stable sales and channels and market. In this relationship, leading enterprise and farmers are the main body of economic interests both sides, and leading enterprise stays in advantage and dominant position in the whole industry. Therefore, leading enterprise produced below interest demands:

First, to save the transaction costs. Leading enterprise changes transaction relationship into the relationship with farmer professional cooperative economic organization and enterprise, thus to reduce the number of transactions and form scale transactions, meanwhile market transactions relationship change into internal cooperation instead of competition, but also save the transaction.

Second, to reduce enterprise business risks. Leading enterprises and farmers form a risk sharing mechanism through methods such as property rights or contract. The industrialization system builds the new model of property relationship, farmers are no longer pure raw material suppliers, but for the average profit, pin in the link sharing.

Third, to avoid opportunism behavior. With more and more high investment asset specificity, farmers and leading enterprises both have access to the other side of quasi rent investment motivation, then the market relationship between alternative business organization to internalization, reduces market transaction uncertainty becomes possible, and overcomes the incompleteness and asymmetry of contract information, so avoid the opportunistic behavior to a certain extent and reduce uncertainty.

\subsection{Interests Demand of Professional Large Family in Farmer Professional Cooperative Economic Organization}

Professional large family, which is also the main force of the current economic organization, has a certain appeal and influence in local, and can play the leading role obviously to attract other farmers to participate in the same industry with them. Professional large family has strongly self-interest to establish farmer professional cooperative economic organization, one is the expansion of the scale in order to form industry to generated economic interests, and another is to achieve self realization needs of spiritual interests. But, this kind of farmer professional cooperative economic organization is more embodied "borrowed its name, selfish interests" of the shell in nature, it is still relatively difficult to promote the common prosperity.

\section{TRANSMUTATION ANALYSIS OF MEMBER INTERESTS DEMANDS OF FARMER PROFESSIONAL COOPERATIVE ECONOMIC ORGANIZATION}

At present, the existence and development motive of farmer professional cooperative economic organization is the inner interest demand of farmers. Therefore, establishing the induction mechanism of interests is the core and key issue to promote sustainable and stable development of farmer professional cooperative economic organization. In fact, in the process of interest transmutation, there are some problems in two aspects:

One is own problems. They are that farmer participation forms lack a sound legal security system, benefit sharing appears unfairness, unequal and mutual interests, and the internal mechanism of benefit sharing is not healthy total loss.

Another is social and environmental issues. They are that the degree of farmer systematize is not high, farmers cannot get more right to speak in the interests to share, and farmer professional cooperative economic organization cannot combine with other industry with less investment cooperation.

\section{ESTABLISHMENT AND ANALYSIS OF DILEMMA MODEL OF BENEFIT SHARING TRANSMUTATION}

\subsection{Establishment model}

Because farmer professional cooperative economic organization is the relationship including integration based on leading enterprise and farmers, it is necessary that benefit sharing will have a conflict. So, how to determine the benefit sharing standards at the level in order to jointly create a brand and increase market share? This involves negotiation 
game process. Therefore, here will give a complete information dynamic model (agricultural enterprise dilemma model) by agricultural enterprises and farmers 2 players. Now make the following hypothesis:

Hypothesis 1: leading enterprises and farmers are the two players with fully rational and complete information, i.e. both sides can observe each other in the process of the game in all of the options.

Hypothesis 2: for a specific event, if two individuals choose to cooperate, then profits is $\boldsymbol{Y}_{i}^{C}(\mathrm{i}=1,2.1$ is agricultural enterprise and 2 is

farmers), if two individuals don't choose to cooperate, profits is $Y_{i}^{N}$, if only one choose to

cooperate, partner profits is $\boldsymbol{Y}_{i}^{a}$ and no partner profits is $\boldsymbol{Y}_{i}^{b}$ (both sides cooperation profits is greater than the both sides cooperation, so $Y_{i}^{C}>Y_{i}^{N}$; when one choose noncooperation, then

no partner profits is greater, $\boldsymbol{Y}_{i}^{b}>\boldsymbol{Y}_{i}^{C}$, but partner profits is less than both sides no cooperation profits, $\left.\boldsymbol{Y}_{i}^{a}<\boldsymbol{Y}_{i}^{N}\right)$, so profits is $\boldsymbol{Y}_{i}^{b}>\boldsymbol{Y}_{i}^{C}>\boldsymbol{Y}_{i}^{N}>\boldsymbol{Y}_{i}^{a}$.

Hypothesis 3: although each individual faces different form and size in each conflicts of interest (game event), it can still put the abstract each game event into a sub game of the game, which will not affect the outcome of the game.

Hypothesis 4: participant preference for time (discount factor) is $\delta$, the probability of participate at the end of each stage is $\mathrm{p}$. the T-stage probability of game is $(1-p)^{t-1}$, the expectation payment in the

T-stage is $(1-p)^{t-1} \pi_{t}$, discount value is $\delta^{t-1}(1-p)^{t}$ ${ }^{-1} \pi_{\mathrm{i} .}$. Let $\delta=\delta(1-\mathrm{p})$, and name it for "important factor". The greater "important factor" is, the stronger of participant preference for time is (means the current selection will have greater influence for the future game), and the smaller the probability of each stage ends is (means the game tends to infinite time game). Figure 1 is the payment matrix of leading enterprises dilemma.

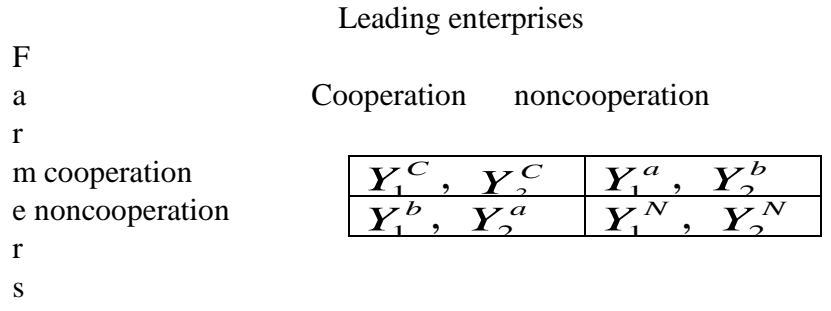

Figure 1 the payment matrix of leading enterprises dilemma

\subsection{Model Analysis}

\subsubsection{Finitely repeated games between leading enterprises}

In the course of the game, if the probability $\mathrm{p}$ at the end of each stage is greater, the final results of the game will be (noncooperation, noncooperation), that is Pareto inefficiency. Its analysis process is that at the last stage considered from the finite time game start, if farmers choose cooperation and leading enterprises choose noncooperation, then $\boldsymbol{Y}_{2}^{b}>\boldsymbol{Y}_{2}^{C}$;

but if farmers choose noncooperation, leading enterprises still choose noncooperation, then $Y_{2}^{N}>Y_{2}^{a}$, so at the last stage whether how to choose the farmer is, leading enterprises will choose noncooperation. Likewise, whether how to choose the leading enterprises, farmers will choose noncooperation. So, as fully rational personal, farmers and leading enterprises are both expected the noncooperation to each other, they always choose noncooperation for the maximization of their own profit consideration. At the last second stage, farmers and leading enterprises expect noncooperation to each other at the next stage, so two rational participants in the current stage both will choose noncooperation, so the first stage may be deduced by analogy. Thus, the equilibrium result of a finitely repeated game is same with one-time game (noncooperation, noncooperation), bilateral cooperation is in dilemma. This is why farmer professional cooperative economic organization has less progress, is also the fundamental obstacle to promote agricultural co-operation.

\subsubsection{Infinitely repeated game between leading enterprises}

\subsubsection{Using "grim strategy"}

"Grim strategy" means choosing cooperation at the beginning or still keeping cooperation until one play chooses noncooperation, from now it chooses noncooperation forever. It is assumed that leading enterprises choose the grim strategy, it cannot use backward induction to solve because of infinitely repeated game. If farmers choose firstly noncooperation at the T-stage, the opportunism behavior of farmers will trigger the punishment of never cooperation from leading enterprises, so farmers profits at the T-stage is $Y_{1}^{b}$, and profits is $Y_{1}^{N}$ at the later stage; of course, if farmers don't choose firstly noncooperation, farmers profits will be $Y_{1}^{C}$ at the each stage. Thus, if the following conditions are met, and given leading enterprises and farmers both choose cooperation: 
$Y_{1}^{b}+\delta Y_{1}^{N}+\delta{ }^{2} Y_{1}^{N}+\ldots \leqq$
$Y_{1}^{C}+\delta Y_{1}^{C}+\delta{ }^{2} Y_{1}^{C}+\ldots$

That is $\quad Y_{1}^{a}+\frac{Y_{1}^{N}}{1-\delta} \leq \frac{Y_{1}^{C}}{1-\delta}$

With this condition, $\delta \geq 1-\frac{Y_{1}^{C}-Y_{1}^{N}}{Y_{1}^{b}}$ 。

That is when important factor $\delta$ meet this conditions, given leading enterprises with grim strategy and without noncooperation firstly, then farmers will not choose noncooperation firstly as well. According to the symmetry of the knowable, given farmers with grim strategy and choosing cooperation firstly, leading enterprises also will choose cooperation. Thus it may be known, the greater $Y_{1}^{b}$ is, the greater $\delta$ is as well. This shows that when the more temptation of interests is, the higher important factor $\delta$ requirement, that means the larger the discount factor $\bar{\delta}$ requirements, the smaller the probability $\mathrm{P}$ of participation at the end of each stage is, resulting in the more difficult to maintain cooperation.

Next, if leading enterprise choose firstly noncooperation, whether farmers are motivated to adhere to the grim strategy for punishment leading enterprises without cooperation. Given leading enterprises adhere to the grim strategy, and once noncooperation will be forever. If farmers choose grim strategy, the payment at the later each stage is $Y_{1}{ }^{N}$, if farmer choose other strategies, the profits at the any single stage will be not more $Y_{1}{ }^{N}$, thus, no matter $\delta$, farmers have the enthusiasm of adhere to the grim strategy. Likewise, leading enterprises adhere to the grim strategy as well, because the grim strategy is a Nash equilibrium for them. But in reality, due to farmers and leading enterprises lack confidence of cooperation forever, and meanwhile imperfect legal system results in short-term behavior of government staff, the important factor $\delta$ is often difficult to get a large enough value, so the grim strategy fails.

Then, how to get rid of the dilemma? The answer is from two-part strategies.

\subsubsection{Using "two-part strategies"}

The content of two-part strategies is two participants choose cooperation at the beginning. At the T-stage, if both of two participants choose cooperation or noncooperation at the (T-1) stage, then continue to choose to cooperation, or else noncooperation.

If both of farmers and leading enterprises choose two-part strategies, infinitely repeated game has two types of sub-game. One is cooperation sub-game, the result of former stage is (cooperation, cooperation) or (noncooperation, noncooperation); another is punishment sub-game, the result of former stage is neither (cooperation, cooperation), nor (noncooperation, noncooperation). If two-part strategies are a perfect equilibrium, it must be under tow kinds of game all constitute a Nash equilibrium.

First, cooperation sub-game

If two-part strategies is a Nash equilibrium of cooperation sub-game, the preference of participants must be cooperation at the T-stage and $(\mathrm{T}+1)$ stage. That means profits from the short-term optimal choice don't exceed the punishment loss at the next stage. At this time, it should meet the following conditions:

$$
\boldsymbol{Y}_{i}^{C}+\delta Y_{i}^{C} \leqq Y_{i}^{b}+\delta Y_{i}^{N}
$$

This is $\delta \geq \frac{Y_{i}^{b}-Y_{i}^{c}}{Y_{i}^{C}-Y_{i}^{N}}$

So, when $\boldsymbol{Y}_{i}{ }^{N} \in\left[\boldsymbol{Y}_{i}^{a}, \frac{(\delta+1) Y_{i}^{C}-Y_{i}^{b}}{\delta}\right]$, conditions is met.

Let $\delta=\frac{1}{2}$, then $Y_{i}^{N} \in\left[Y_{i}^{a}, 3 Y_{i}^{C}-2 Y_{i}^{b}\right]$.

Second, punishment sub-game

If leading enterprises choose noncooperation, then farmers choose noncooperation at this stage, cooperation at the next stage, there is no other choices (if cooperation at this stage, the profits is less than noncooperation, and will continue punishment sub-game at the next stage). No matter the value of delta is, this kind of choice is a subgame Nash equilibrium. Combining the above two types sub-game conditions, it can be known when $\boldsymbol{Y}_{i}{ }^{N} \in\left[\boldsymbol{Y}_{i}^{a}, \frac{(\delta+1) Y_{i}^{C}-Y_{i}^{b}}{\delta}\right]$, two-part strategies can make sure the emergence of the sub-game perfect Nash equilibrium (cooperation, cooperation) between farmers and leading enterprises. Compared with the grim strategy, when $\delta=\frac{1}{2}$, the equilibrium can achieve by two-part strategies. Therefore, twopart strategies have more possibility to solve the dilemma.

\section{CONCLUSION}

In short, the establishment of farmer professional cooperative economic organization is not only for meeting farmers' profits, but also for other members. It is a kind of platform to meet profits. Along with the evolution of the internal structure interest in farmer professional cooperative economic organization, patronage and owner interests may conflict. But with the continuous progress of the internal relationship of members, member interests 
should also be the evolution of vertical integration relationship based on farmer professional cooperative economic organization. That will take more advantage for farmers and others members, and eventually "sharing resources, sharing of benefits and risk sharing".

\section{ACKNOWLEDGEMENT}

This paper is supported by Marketing Channels Capacity Study of Farmer Professional Cooperative Economic Organization in Western Area Based on Vertical Organizational Relationship (71163024) from National Natural Science Foundation of China, The Inner Mongolia Autonomous Region Higher School "innovation team development plan--the circulation of agricultural products "(NMGIRT1306) and Safety Study of animal products in Inner Mongolia Based on SCP
(NJSY14120) from the Foundation of Inner Mongolia Education Department.

\section{REFERENCES}

[1] $\mathrm{Xu}$ dexin. Agricultural Industrialization: the source of leading enterprises for healthy growth---theoretical analysis and empirical research. Rural Economy. 2004, No.8, pp.40-41

[2] Hao chaohui. Problem Analysis of the Benefit Mechanism between Leading Enterprises and Farmers Based on Agricultural Industrialization. Rural Economy. 2004, No.7, pp. $45-47$

[3] Li yanpu. Motivation Research on Farmer Professional Cooperative Based on Interests Demand. Journal of Anhui Agricultural Sciences. 2012 Vol40, No.9, pp.5660-5662

[4] Sun yafan. Analysis of the Benefit Mechanism and Influence Factors of Farmers Professional

[5] Cooperative Economic Organization---An Empirical Study Based on Jiangsu Province. Issues in Agricultural Economy. 2008, No.9, pp.48-56 